\title{
Comparative evaluation of microdiscectomy only, autograft fusion, polymethylmethacrylate interposition, and threaded titanium cage fusion for treatment of single-level cervical disc disease: a prospective randomized study in 125 patients
}

\author{
Christian B. Bärlocher, M.D., Alain Barth, M.D., Joachim K. Krauss, M.D., \\ RalPh BingGeli, M.D., AND RolF W. SEILER, M.D.
}

Department of Neurosurgery, Inselspital, University of Berne, Switzerland

\begin{abstract}
Object. The need for interbody fusion or stabilization after anterior cervical microdiscectomy is still debated. The objectives of this prospective randomized study were 1) to examine whether combined interbody fusion and stabilization is more beneficial than microdiscectomy only (MDO) and 2) if fusion is found to be more beneficial than MDO, to determine which is the best method of fusion by comparing the results achieved using autologous bone graft (ABG), polymethylmethacrylate (PMMA) interposition, and threaded titanium cage (TTC).

Methods. A total of 125 patients with a single-level cervical disc disease were included in this prospective study. All patients were randomized and assigned to one of the four following groups: Group 1 (33 patients), MDO; Group 2 (30 patients), microdiscectomy followed by ABG; Group 3 (26 patients), microdiscectomy followed by injection of PMMA; and Group 4 (36 patients), microdiscectomy followed by placement of a TTC. Clinical outcome according to Odom criteria was summarized as 1) excellent and good or 2) satisfactory and poor. One-year follow-up examination was performed in 123 patients. Patients in the TTC group experienced a significantly better outcome 6 months after surgery (92\% excellent and good results) compared with those in the MDO and ABG groups (72.7 and 66.6\% excellent and good results, respectively). Twelve months after surgery there was still a significant difference in outcomes between the TTC group (94.4\% excellent and good results) and the MDO group (75.5\% excellent and good results). Outcome in patients treated with PMMA was comparable with that in those treated with TCC after $6(91.6 \%)$ and 12 months (87.5\%), but no segmental fusion was achieved. Differences compared with MDO and ABG were, however, not significant, which may be related to the smaller number of patients in the PMMA group.

Conclusions. Interbody cage-assisted fusion yields a significantly better short- and intermediate-term outcome than MDO in terms of return to work, radicular pain, Odom criteria, and earlier fusion. In addition, the advantages of interbody cages over ABG fusion included better results in terms of return to work, Odom criteria, and earlier fusion after 6 months. These results suggest that interbody cage-assisted fusion is a promising therapeutic option in patients with single-level disc disease. Polymethylmethacrylate seems to be a good alternative to interbody cage fusion but is hindered by the absence of immediate fusion.
\end{abstract}

\section{KEY WoRDS - intervertebral disc interbody cage $•$ spinal fusion • \\ - disc herniation - discectomy - cervical spine • polymethylmethacrylate}

The need for interbody fusion after cervical microdiscectomy is still debated, and the option of MDO has been advocated by many authors who have reported acceptable MDO-related results. ${ }^{3,20,25,28}$ The concept of reconstructing the disc space, however, remains attractive to many other surgeons, and interbody fusion following microdiscectomy for cervical myelopathy or nerve root compression is an accepted surgical adjunct to help minimize postoperative morbidity. ${ }^{11,12}$ The advantages of interbody fusion include: 1) maintenance of cervical alignment; 2) arrest of spur formation or resorption of spurs; 3) elimination of

Abbreviations used in this paper: $\mathrm{ABG}=$ autologous bone graft; $\mathrm{CT}=$ computerized tomography; $\mathrm{DDD}=$ degenerative disc disease; LOS = length of stay; MDO = microdiscectomy only; PMMA = polymethylmethacrylate; $\mathrm{TTC}=$ threaded titanium cage; VAS $=$ visual analog scale. potential instability; and 4) preservation of disc height and angulation, thereby reducing potential compromise of the neural foramen compromise.

The ideal fusion substrate remains a controversial issue. Autologous bone graft was used in the original descriptions of fusion procedures for the cervical spine and is still the standard and most widely used fusion substrate ${ }^{4-6,8}$ Single-level fusion rates with this method range from 83 to $97 \% .3,21,23$ One important disadvantage associated with $\mathrm{ABG}$ is discomfort at the iliac crest, the site at which bone graft is harvested. Polymethylmethacrylate was introduced later as a substitute for the removed intervertebral disc to simplify and improve the surgical procedure. ${ }^{10}$ The stability of the PMMA-assisted fusion was reported to be as high as 90 to $98 \%$, thus comparing well with the results of ABG. Whether a true osseous fusion of the stabilized segment is achieved, however, remains controversial. 
Recently, interbody fusion in which TTCs or carbon fiber cages are used has been introduced in cervical spine surgery as an alternative method to ABG or PMMA interposition for stabilization following anterior microdiscectomy.

This clinical study was designed to evaluate whether combined interbody fusion and stabilization is more beneficial to patients than MDO, and, if it is, to determine the best method of fusion.

\section{CLINICAL MATERIAL AND METHODS}

\section{Study Design}

A consecutive series of patients with radiculopathy secondary to single-level cervical disc disease and no cervical myelopathy were prospectively randomized into four treatment groups before surgery and were followed for 1 year. These four groups included: 1) MDO; 2) microdiscectomy with ABG; 3) microdiscectomy with PMMA interposition; and 4) microdiscectomy with placement of a TTC (BAK/C; Sulzer Medica, Spine Tech, Münsingen, Switzerland). All procedures were performed at the same institution by five different surgeons. Patients who fulfilled the inclusion criteria were informed about the study and were randomly assigned to one of the four treatment groups. Preoperatively, patients were informed about the result of the randomization and about the proposed treatment. Each patient agreed with the randomization and provided written consent to the operation.

\section{Patient Selection}

Patients were selected for surgery based on results of examination, history of cervicobrachialgia refractory to nonoperative treatment and imaging studies, as well as the presence of a single-level cervical disc disease between C-3 and T-1. Radiculopathies secondary to softdisc herniation with or without osteophytes were present in all patients. Exclusion criteria were significant vertebral instability, myelopathy, systemic infection or metabolic disease, active malignancy, symptomatic DDD of two or more cervical segments, acute trauma, and rheumatoid disease.

One hundred twenty-five patients (74 men, 51 women; mean age 50.4 years [range 24-84 years]) participated in the study.

\section{Clinical Evaluation}

Preoperatively, all patients completed study forms including questions regarding work and daily function, as well as VAS rating the extent of pain. ${ }^{18}$ The standard neurological examination included a thorough documentation of three cervical symptom clusters: 1) neck pain, 2) radicular pain, and 3) neurological deficits.

The follow-up clinical examination included evaluation of the effects on pain and neurological status based on the VAS score and the three preoperative cervical symptom clusters. Preoperative status was evaluated at 2, 6, and 12 months. Social and functional outcomes were assessed by evaluating work capacity and according to the criteria of Odom, et al. ${ }^{19}$ Questionnaires were updated at each visit, and patients were also asked to describe their perception of the result of surgery.
Radiological follow-up evaluation was performed using conventional plain radiographs and reconstructed CT scans of the cervical spine at 6 months. At 12 months flexion-extension x-ray films were obtained. Radiographs were reviewed by an independent radiologist. Failed fusion was defined as absorption of bone adjacent to the bone graft or cage, and motion of $2^{\circ}$ or greater on flexion-extension x-ray films. Fusion was assessed when an osseous trabecular bridge was visible on the CT scan reconstructions. Loss of surgically restored disc height and loss of sagittal balance were measured.

\section{Surgical Procedure}

Patients underwent surgery in the supine position after induction of general anesthesia. Anterior cervical microdiscectomy and/or resection of osteophyte(s) was accomplished in every case, with exposure of the dura mater and origin of the nerve roots bilaterally. In the MDO group, no material was inserted into the intervertebral space. In the ABG group, an iliac crest autograft was obtained using a Caspar saw. In the TTC group, the interspace was drilled using a 10-mm drill. Tapping and placement of a $10 \times$ 12-mm cage filled with osteoconductive bone material (Tutoplast; Neutromedics AG, Cham, Switzerland) was accomplished using fluoroscopic guidance and a guide tube system. In the PMMA group, gelfoam was used to protect the dura and nerve roots against thermic injury before inserting the PMMA.

Postoperatively, all patients were instructed to wear a soft cervical collar during the first 3 weeks. Surgery-related variables such as hospital LOS, blood loss, and operating time were recorded. Complications and morbidity, such as recurrent laryngeal nerve palsy, postoperative hematoma, or donor site pain were recorded.

\section{Statistical Analysis}

The two-tailed Fisher exact test and the Kruskal-Wallis nonparametric analysis of variance test including the Dunn multiple comparison test were conducted to evaluate the intergroup demographic equivalence and to examine the intergroup differences in outcomes. Statistical significance was set at $\mathrm{p}$ less than 0.05 .

\section{RESULTS}

\section{Differences in Patient Characteristics}

One hundred twenty-five patients participated in the study. There were 74 men and 51 women, who ranged in age from 24 to 84 years (mean $50.5 \pm 11.4$ years [standard deviation]). Adequate follow-up data were available in $123(98.4 \%)$ of the 125 patients. Two patients (in the PMMA treatment arm [Group 3]) were lost to follow up. One of these patients died 4 months postoperatively of causes unrelated to the spine surgery.

Patient characteristics are presented in Table 1. There were no significant intergroup differences regarding baseline characteristics except that patients in the MDO treatment group suffered significantly less cervical pain preoperatively than did those in the TTC and PMMA treatment groups $(75.7 \%$ in the MDO group; $97.2 \%$ in the TTC group; $100 \%$ in the PMMA group; $\mathrm{p}<0.02$ ) despite ran- 
TABLE 1

Characteristics and surgery-related variables in 125 patients with one-level cervical disc disease

\begin{tabular}{|c|c|c|c|c|}
\hline Characteristic & MDO & $\mathrm{ABG}$ & PMMA & TTC \\
\hline no. of patients & 33 & 30 & 26 & 36 \\
\hline age (yrs) & $51.1 \pm 12.5$ & $47.3 \pm 11.5$ & $52.2 \pm 10.8$ & $50.5 \pm 13.4$ \\
\hline female $(\%)$ & 41 & 40 & 50 & 33 \\
\hline height $(\mathrm{cm})$ & $170.9 \pm 8.6$ & $170 \pm 8.6$ & $170 \pm 8.9$ & $171 \pm 6.6$ \\
\hline weight (kg) & $73.9 \pm 13$ & $74 \pm 12.9$ & $73.4 \pm 12.5$ & $72.9 \pm 10.8$ \\
\hline smoking habit (\%) & 30 & 37 & $38-10$ & $31-1$ \\
\hline prior surgery (\%) & 6 & 7 & 0 & 11 \\
\hline cervical pain (\%) & $75.7 *$ & 86.6 & 100 & 97.2 \\
\hline radicular pain (\%) & 100 & 93.3 & 100 & 94.4 \\
\hline neurological deficits (\%) & 84.8 & 73.3 & 76.9 & 77.7 \\
\hline \multicolumn{5}{|l|}{ affected level } \\
\hline C $3-4$ & 0 & 0 & 0 & 1 \\
\hline C4-5 & 1 & 5 & 1 & 2 \\
\hline C5-6 & 9 & 9 & 6 & 15 \\
\hline C6-7 & 20 & 14 & 18 & 17 \\
\hline $\mathrm{C} 7-\mathrm{T} 1$ & 3 & 2 & 1 & 1 \\
\hline LOS (days) & $7.6 \pm 2.1$ & $7.5 \pm 1.8$ & $6.8 \pm 1.3$ & $7 \pm 1.1$ \\
\hline op time (mins) & $82.6 \pm 11.2 \dagger$ & $99.8 \pm 9.8 \div \S$ & $89 \pm 11.6 \|$ & $75.8 \pm 14.8$ \\
\hline blood loss (ml) & $49.7 \pm 12.6+\|$ & $70.7 \pm 17.8$ & $58.3 \pm 17.6$ & $62.8 \pm 14.9$ \\
\hline
\end{tabular}

* Significant difference between MDO, TTC and PMMA $(\mathrm{p}<0.02)$.

$\dagger$ Significant compared with ABG treatment $(\mathrm{p}<0.001)$.

$¥$ Significant compared with TTC treatment $(\mathrm{p}<0.05)$.

$\S$ Significant compared with PMMA treatment $(\mathrm{p}<0.05)$.

$\|$ Significant compared with TTC treatment $(\mathrm{p}<0.01)$.

domization. The mean preoperative duration of pain in all groups was 8 months (range $0.5-72$ months). Sixty-one percent of the patients did not work at the time of the operation. The mean duration of preoperative work incapacity was 1.8 months (range $0-60$ months).

\section{Surgery-Related Variables}

Surgery-related variables are also summarized in Table 1. The median hospital LOS was 7 days (range 4-14 days). Currently, the LOS is shorter (4-5 days). A significant difference in the operating time was found. The TTC treatment group demonstrated the shortest mean operating time $(75.8 \pm 14.8$ minutes [mean \pm standard deviation]), which was significantly shorter than those observed in the PMMA and the ABG treatment groups $(p<0.01)$. An explanation for the longer operating time in the MDO group is that wide bilateral foraminotomies were performed after microdiscectomy. The difference in blood loss between the four groups was also significant; it was significantly less in the MDO group than in the ABG $(p<0.001)$ and the TTC groups $(\mathrm{p}<0.01)$.

\section{Surgery-Related Complications}

Three patients (2.4\%) suffered a transient recurrent laryngeal nerve palsy: one in the MDO group, one in the ABG group, and one in the PMMA group. One patient in the $\mathrm{ABG}$ group experienced an ulnar nerve palsy. Five $(17 \%)$ of 30 patients treated with ABG suffered donor site morbidity: one patient suffered a fracture of the iliac crest postoperatively; two patients developed a hematoma at the iliac crest, one patient complained of meralgia paresthetica, and one patient reported persistent pain.

Three patients $(2.4 \%)$ had to undergo reoperation. Bone graft luxation occurred in one ABG-treated patient who underwent subsequent fusion and plate-assisted fixation.
A patient in the MDO treatment group underwent surgical treatment of a disc herniation at a second level. Another patient in the MDO group developed marked postoperative vertebral instability with subluxation of the surgically treated level (Fig. 1), which had to be fused and stabilized.

\section{Postoperative Outcome}

Clinical Outcome. Clinical outcomes regarding the three cervical symptom clusters (neck pain, radicular pain, and neurological deficits) at 2, 6, and 12 months postop-

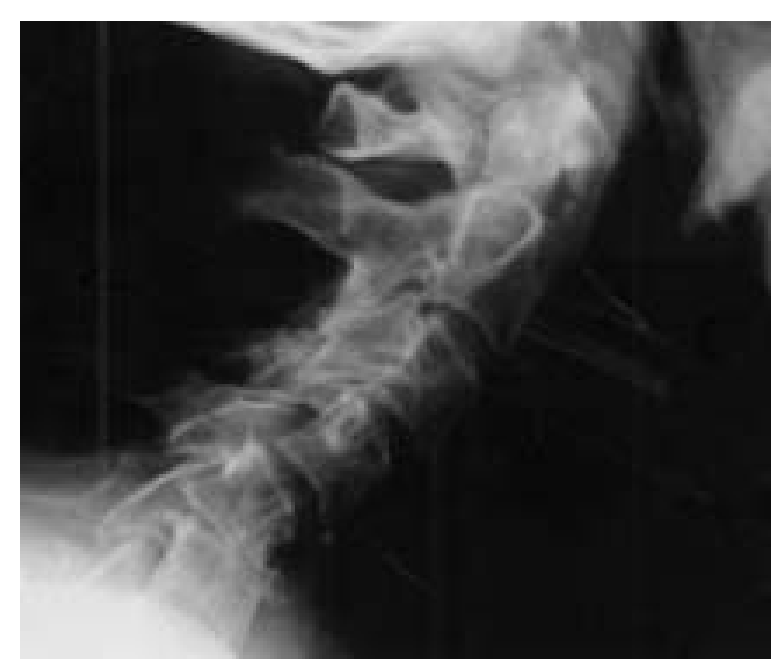

Fig. 1. Lateral radiograph obtained 2 months after MDO, revealing development of a kyphotic deformity $\left(31^{\circ}\right)$; the patient experienced marked neck pain, but no neurological deficits were present. This patient underwent surgical revision in which a two-level operation with interbody cages and an anterior plate was performed. 
eratively are presented in Table 2 . A significant difference was found at 12 months in radicular pain between patients in the MDO group and those in the TTC group $(\mathrm{p}<0.05)$.

Functional Outcome. The functional outcome (assessment of work incapacity and Odom criteria) is detailed in Table 3. Six months postoperatively, TTC-treated patients returned significantly earlier to work than those in the MDO and ABG groups $(\mathrm{p}<0.05)$. At 1 year postoperatively, only $2.8 \%$ of the TTC-treated patients had not returned to work, compared with $12.1 \%$ of the MDO- and $16.7 \%$ of the ABG-treated patients; however, this was no longer significant. At 6-month follow up, there was a trend for better outcome in the TTC group compared with the MDO group $(p=0.05)$ according to Odom criteria. At 12-month follow up, evaluation of Odom criteria revealed significantly better outcome in the TTC group than in the MDO group $(p<0.02)$. Outcome in the ABG group was similar to that in the MDO group, with no significant differences. There was a statistically significant difference in outcome between ABG and TTC at 6 months $(\mathrm{p}<0.02)$, although not at 12 months. Outcome of PMMA-treated patients was similar to that in the TTC-treated patients, with no statistically significant differences.

Radiological Outcome. Fusion rates in the TTC group were statistically significantly higher after 6 months than those in the MDO and ABG groups ( $\mathrm{p}<0.03$; Table 4). The studies in Fig. 2 upper left, upper right and lower right demonstrate a solid fusion 6 months postoperatively in patients in the MDO, ABG and TTC groups, respectively. No evidence of osseous fusion was demonstrated in the PMMA-treated patients (Fig. 2 lower left). Twelve months postoperatively, a significantly lower subsidence rate was demonstrated in the TTC group than in the MDO group (mean $0.74 \mathrm{~mm}$ [range 0-6 $\mathrm{mm}$ ] compared with mean $1.27 \mathrm{~mm}$ [range $0-3 \mathrm{~mm}$ ]); $\mathrm{p}<0.05$ ), and also in the $\mathrm{ABG}$ group (mean $2.26 \mathrm{~mm}$ [range $0-5 \mathrm{~mm}$ ]), $\mathrm{p}<$ 0.001; Fig. 3). There were no significant differences in the subsidence depth between the TTC group and the PMMA group (mean 0.74 and $0.79 \mathrm{~mm}$, respectively, range $0-4$

TABLE 2

Percentage of improved clinical outcome in 123 patients

\begin{tabular}{lllll}
\hline \hline & \multicolumn{4}{c}{ Percentage of Improvement } \\
\cline { 2 - 5 } & $\begin{array}{c}\text { MDO } \\
(33\end{array}$ & $\begin{array}{c}\text { ABG } \\
(30\end{array}$ & $\begin{array}{c}\text { PMMA } \\
(24 \\
\text { patients) }\end{array}$ & $\begin{array}{c}\text { TTC } \\
\text { patients })\end{array}$ \\
patients)* & patients $)$ \\
\hline Variable & & & & \\
neck pain (VAS) & 45.5 & 20 & 27 & 47.3 \\
at 2 mos & 53.6 & 53.4 & 58.4 & 72.3 \\
at 6 mos & 64 & 50 & 62.5 & 72.3 \\
at 12 mos & & & & \\
radicular pain (VAS) & 78.8 & 66.7 & 88.5 & 86.2 \\
at 2 mos & 78.8 & 76.7 & 79.2 & 91.7 \\
at 6 mos & $81.9 \dagger$ & 86.7 & 87.5 & 97.3 \\
at 12 mos & & & & \\
neurologic deficits & 45.5 & 63.4 & 63.4 & 63.9 \\
at 2 mos & 63.7 & 70 & 83.4 & 72.3 \\
at 6 mos & 72.8 & 76.7 & 79.2 & 80.6 \\
at 12 mos & & & & \\
\hline
\end{tabular}

* Two patients were lost to follow up.

$\dagger$ Significant compared with TTC $(\mathrm{p}<0.05)$.
TABLE 3

Summary of functional outcome in 123 patients

\begin{tabular}{|c|c|c|c|c|}
\hline Variable & $\begin{array}{c}\text { MDO } \\
(33 \\
\text { patients })\end{array}$ & $\begin{array}{c}\text { ABG } \\
(30 \\
\text { patients })\end{array}$ & $\begin{array}{c}\text { PMMA } \\
(24 \\
\text { patients)* }\end{array}$ & $\begin{array}{c}\text { TTC } \\
(36 \\
\text { patients })\end{array}$ \\
\hline \multicolumn{5}{|l|}{ work incapacity (\%) } \\
\hline at $6 \mathrm{mos}$ & $18.1 \dagger$ & $27.2 \dagger$ & 8.3 & 5.5 \\
\hline at $12 \mathrm{mos}$ & 12.1 & 16.7 & 4.2 & 2.8 \\
\hline \multicolumn{5}{|l|}{$\begin{array}{l}\text { Odom criteria }(\%) \\
\text { at } 6 \mathrm{mos}\end{array}$} \\
\hline excellent/good & $72.7 \ddagger$ & $66.6 \dagger$ & 91.6 & 91.6 \\
\hline $\begin{array}{l}\text { fair/poor } \\
\text { at } 12 \mathrm{mos}\end{array}$ & $27.3^{\circ}$ & 33.3 & 8.4 & 8.4 \\
\hline excellent/good & $75.5 \dagger$ & 80 & 87.5 & 94.4 \\
\hline fair/poor & 24.5 & 20 & 12.5 & 5.6 \\
\hline
\end{tabular}

* Two patients were lost to follow up.

$\dagger$ Significant compared with TTC $(\mathrm{p}<0.05)$

$\ddagger$ Not significant compared with TTC $(\mathrm{p}=0.05)$.

$\mathrm{mm})$. Only one patient $(2.7 \%)$ in the TTC group had a slight kyphosis of $3^{\circ}$ as a sign of postoperative loss of sagittal balance. Three patients treated with PMMA (12.5\%) developed postoperative kyphosis, compared with eight patients $(24.2 \%)$ in the MDO group and one patient $(3.3 \%)$ in the ABG group. The range of kyphosis in all patients in the different groups was 2 to $8^{\circ}$. Only one patient in the MDO group developed a clinically relevant kyphosis at 2 months postoperatively (Fig. 1). This patient with a kyphotic deformity of $31^{\circ}$, underwent a second procedure in which cages and an anterior plate were placed, as previously mentioned.

\section{DISCUSSION}

Since the introduction of anterior approaches to the cervical spine for the surgical treatment of DDD, controversies have developed regarding the necessity of fusion following anterior cervical discectomy, the use of allograft instead of autologous bone for fusion, and, recently, the placement of interbody fusion cages for uncomplicated disc disease. ${ }^{1,11,25}$ The authors of several studies have demonstrated that anterior discectomy can be performed safely and effectively with or without fusion, with allograft or

TABLE 4

Summary of radiological outcome in 123 patients

\begin{tabular}{|c|c|c|c|c|}
\hline Variable & $\begin{array}{c}\text { MDO } \\
(33 \\
\text { patients })\end{array}$ & $\begin{array}{c}\text { ABG } \\
(30 \\
\text { patients })\end{array}$ & $\begin{array}{c}\text { PMMA } \\
(24 \\
\text { patients })^{*}\end{array}$ & $\begin{array}{c}\text { TTC } \\
(36 \\
\text { patients })\end{array}$ \\
\hline \multicolumn{5}{|l|}{ fusion rate $(\%)$} \\
\hline at $6 \mathrm{mos}$ & $60.6 \dagger$ & $65.3 \dagger$ & no fusion & 86.1 \\
\hline at $12 \mathrm{mos}$ & 93.3 & 93.3 & no fusion & 97.2 \\
\hline $\begin{array}{l}\text { loss of disc height } \\
(\mathrm{mm}) \text { at } 12 \mathrm{mos}\end{array}$ & $1.27 \dagger$ & $2.26 \ddagger$ & 0.79 & 0.74 \\
\hline $\begin{array}{l}\text { kyphosis (range, } \\
2-31^{\circ} \text { ) at } 12 \mathrm{mos}\end{array}$ & 24.2 & 3.3 & 12.5 & 2.7 \\
\hline
\end{tabular}

* Two patients were lost to follow up.

$\uparrow$ Significant compared with TTC $(\mathrm{p}<0.05)$

$\ddagger$ Significant compared with TTC $(\mathrm{p}<0.001)$. 


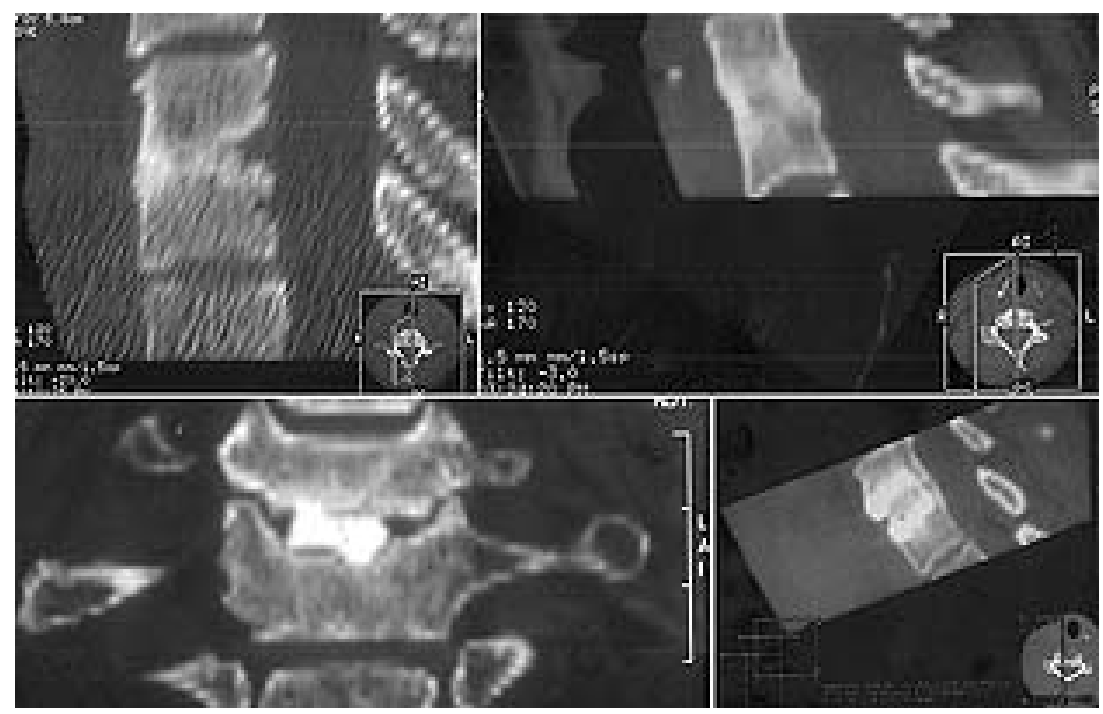

Fig. 2. A reconstructed CT scan obtained 6 months postoperatively. Fusion was assessed when an osseous trabecular bridge such as the one seen in Fig. 2 upper left was visible. Upper Left: Microdiscectomy only. Upper Right: Autograft-assisted fusion. Lower Left: Polymethylmethacrylate interposition; no fusion developed. Lower Right: Threaded titanium cage-assisted fusion.

autograft, and with or without placement of an anterior plate system with apparently similar success rates and a low incidence of permanent side effects. ${ }^{8,14,15,23,27,29,32} \mathrm{Al}$ varez and Hardy ${ }^{1}$ and van Limbeek, et al., ${ }^{31}$ performed a systematic literature review to identify the best method for single-level anterior cervical interbody fusion. Their analysis, however, did not allow firm conclusions to be drawn.

Microdiscectomy alone and that combined with ABG, the most commonly performed procedures for single-level disc disease, have potential pitfalls. ${ }^{11}$ Some authors believe that surgical fusion after single-level discectomy is unnecessary in selected patients..$^{20,25,30}$ Savolainen, et al., ${ }^{25}$ who evaluated discectomy alone compared with discectomy with bone graft fusion with or without a plate, reported better short-term results in the patients who underwent fusion. The long-term outcome of discectomy alone, however, was as favorable as that achieved in patients in whom fusion was also performed, except for donor site pain and kyphosis. Our results in MDO-treated patients are comparable with those described earlier. Savolainen, et al., ${ }^{25}$ reported that $67 \%$ of patients experienced a good outcome after 6 months and that $76 \%$ experienced a good outcome at final follow-up examination 4 years postoperatively. Van den Bent, et al., ${ }^{30}$ found a similar proportion of good results $(77 \%)$ after MDO. No significant differences in the long-term outcome were detected between MDO and ABG-assisted fusion. The only study in which a higher proportion of good MDO-related outcome (96\%) was demonstrated has been reported by Plötz, et al. ${ }^{20}$ These authors, however, included patients exclusively with softdisc herniation without spondylosis. In contrast, in the present report signs of segmental osseous degenerative changes were demonstrated in approximately $50 \%$ of patients. Microdiscectomy without fusion has the inherent risk of pseudarthrosis (10-29\%), progressive kyphosis, foraminal narrowing, and late symptomatic recurrences, although the clinical impact of postoperative foraminal narrowing and kyphosis has not yet been determined. ${ }^{6,11}$ 14,25 Cervical fusion in which autologous bone graft, derived from iliac crest, is used generally yielded satisfactory outcomes $(70-88 \%) .^{7,9-12,21-23}$ Similar to those in MDO, however, kyphotic deformities, graft collapse with pseudarthrosis, and recurrent symptoms can occur. In addition, persistent donor site pain may be a problem in more than $30 \%$ of patients. ${ }^{9,11,12,14,25,26}$

Polymethylmethacrylate-assisted fusion seems to be a good alternative, although in earlier studies the authors failed to show significant differences compared with other surgical procedures. ${ }^{4,24,30}$ Like TCC PMMA has the advantage of avoiding morbidity caused by iliac crest graft harvesting. Postoperative stability has been described in 90 to $98 \%$ of patients, ${ }^{4,24}$ but a true osseous fusion of the stabilized segment remains questionable, and requires

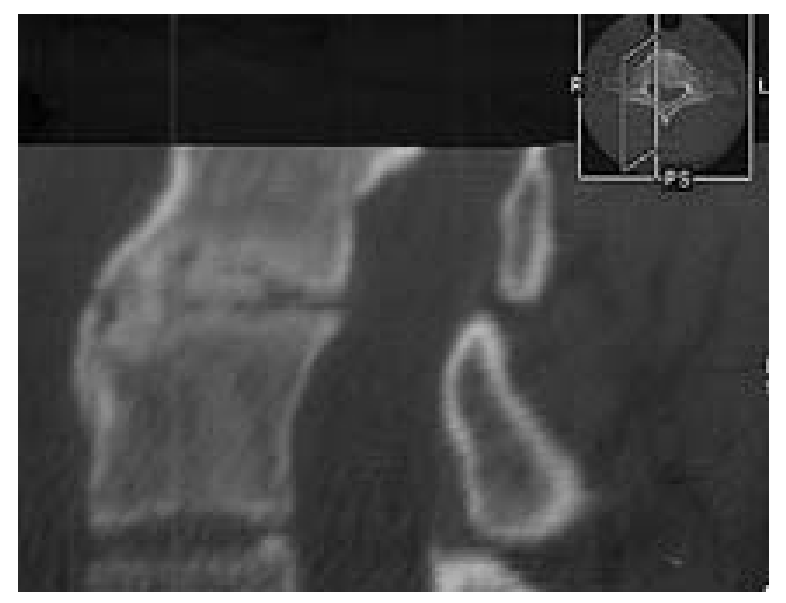

Fig. 3. A reconstructed CT scan obtained 6 months postoperatively revealing autograft collapse and pseudarthrosis. 
much more time to develop. Late fusion, nevertheless, has been reported 15 years postoperatively in approximately $90 \%$. ${ }^{4}$ The only prospective published study on the use of PMMA-assisted fusion is the study conducted by van den Bent, et al. ${ }^{30}$ This group found no significant difference between PMMA-assisted fusion and MDO. Preoperative neck pain resolved earlier when PMMA was used, but the difference was temporary and clinically insignificant. The use of PMMA resulted in a significantly lower rate of osseous union, and more frequent migration of PMMA into adjacent vertebrae occurred. ${ }^{33}$ In our study, clinical outcome in the PMMA treatment group was comparable with that in the TCC group, but segmental fusion was not achieved. When PMMA was compared with MDO and $\mathrm{ABG}$, however, no significant differences were found, which may be related to the smaller number of patients in the PMMA group.

To our knowledge, there are only three published prospective studies regarding the use of cervical interbody fusion cages. ${ }^{2,11,12}$ In all three studies the authors showed that TTC is safe and effective in the treatment of cervical DDD, and they reported long-term results comparable with those achieved using anterior autologous bone graftassisted fusion; however, it avoids significantly donor site morbidity. In the current study evaluating four different methods of cervical microdiscectomy, significantly better results at 1 year postoperatively were shown using TTC than MDO. In addition, results obtained at 6 months were better compared with those achieved in the ABG group. The improved outcome of TTC compared with MDO was strongly correlated with a better initial postoperative segmental stabilization (fusion, subsidence, and kyphosis). This allowed a significantly earlier return to work, thus demonstrating its cost effectiveness. The strong correlation of better outcome with a greater initial postoperative segmental stabilization has also been indicated by other authors. ${ }^{3,25}$ Early stabilization of the surgically treated segment with a plate after ABG increases fusion rates, limits subsidence and kyphotic deformities, and allows earlier return to work. ${ }^{3,25}$ The rate of postoperative morbidity associated with TCC is lower than that with ABG. This is probably because of various factors: the absence of donor site pain, the smaller risk of device-related luxation, and the development of fewer kyphotic deformities. ${ }^{11,12,16,17}$ Subsidence of a TTC into the adjacent cervical vertebrae is possible. Nevertheless, should this occur it will still provide partial support, whereas this is not the case when subsidence occurs in conjunction with autografts or simple discectomy. ${ }^{13}$ We think that the higher subsidence rate in ABG and MDO is the cause of the higher incidence of radicular pain at 1 year postoperatively. The lower subsidence rate associated with the TCC appears to lead to a better fusion compared with $\mathrm{ABG}$ and MDO treatments.

In our opinion, interbody cage fusion yields a significantly better short- and intermediate-term outcome than MDO and ABG in the treatment of single-level cervical disc disease. The main advantages of interbody cage-assisted fusion appear to be: 1) immediate restoration and maintenance of disc height and the height of the foramen, as well as the reduced risk of subsidence; 2 ) better immediate stabilization of the segment; 3 ) earlier bone fusion (first 6 months); 4) prevention of kyphosis; 5) ease of use; and 6) the low morbidity rate. Which is the ideal cage? The TCCs were the first interbody cages available on the European market, but currently a variety of rectangular carbon fiber cages and titanium cages with spikes as interbody spacers can be used. Bartels, et al., ${ }^{2}$ recently studied a rectangular carbon fiber cage in 13 consecutive patients with symptomatic cervical disc herniation. They reported 1-year follow-up results on the beneficial effect of these cages with regard to restoration of foraminal height and lordosis, as well as the near absence of risk of subsidence. In a biomechanical study, interbody spacers had a significantly lower tendency to subside than TTCs (BAK/C). The pullout strength, however, was higher with TTCs. Furthermore, subsiding TCCs did provide partial support, whereas subsiding rectangular interbody spacers did not. ${ }^{33}$ A possible advantage of wedge-shaped interbody spacers may be a better restoration of lordosis. ${ }^{13}$ Whether these biomechanical considerations play an important role in the clinical context remains to be determined.

\section{CONCLUSIONS}

Based on the results of the present study, fusion with interbody cages yields a significantly better short- and intermediate-term outcome than in the treatment of singlelevel DDD of the cervical spine in terms of the following parameters: 1) return to work, 2) radicular pain, 3) Odom criteria, and 4) earlier fusion. The better outcome of interbody cages compared with MDO was strongly correlated with a greater initial postoperative segmental stabilization. In addition, the advantages of interbody cages over ABGassisted fusion, in terms of these four parameters, were only observed at the 6-month follow up.

These results suggest that interbody cage-assisted fusion is a promising therapeutic option in patients with single-level disc disease. Polymethylmethacrylate seems to be a good alternative to interbody cage-assisted fusion, although it is hindered by not providing immediate fusion.

\section{Acknowledgment}

We thank H. R. Widmer, Ph.D., for assistance in the statistical analysis of the data.

\section{References}

1. Alvarez JA, Hardy RW Jr: Anterior cervical discectomy for one- and two-level cervical disc disease: the controversy surrounding the question of whether to fuse, plate, or both. Crit Rev Neurosurg 9:234-251, 1999

2. Bartels RH, Donk R, van Dijk Azn R: Height of cervical foramina after anterior discectomy and implantation of a carbon fiber cage. J Neurosurg 95 (Suppl 1):40-42, 2001

3. Bishop RC, Moore KA, Hadley MN: Anterior cervical interbody fusion using autogeneic and allogeneic bone graft substrate: a prospective comparative analysis. J Neurosurg 85: 206-210, 1996

4. Böker DK, Schultheiss R, Probst EM: Radiologic long-term results after cervical vertebral interbody fusion with polymethyl methacrylat (PMMA). Neurosurg Rev 12:217-221, 1989

5. Caspar W, Geisler FH, Pitzen T, et al: Anterior cervical plate stabilization in one- and two-level degenerative disease: overtreatment or benefit? J Spinal Disord 11:1-11, 1998

6. Cloward RB: The anterior approach for removal of ruptured cervical disks. J Neurosurg 15:602-617, 1958 
7. Dowd GC, Wirth FP: Anterior cervical discectomy: is fusion necessary? J Neurosurg 90 (Suppl 1):8-12, 1999

8. Gaudinez RF, English GM, Gebhard JS, et al: Esophageal perforations after anteriorcervical surgery. J Spinal Disord 13: 77-84, 2000

9. Geer C, Selden NR, Papadopoulos SM: Anterior cervical plate fixation in the treatment of single-level cervical disc disease. J Neurosurg 90:410A, 1999 (Abstract)

10. Grote W, Röttgen P: Die ventrale Fusion bei der zervikalen Osteochondrose und ihre Behandlungsergebnisse. Acta Neurochir 16:218-240, 1967

11. Hacker RJ: A randomized prospective study of an anterior cervical interbody fusion device with a minimum of 2 years of follow-up results. J Neurosurg 93 (Suppl 2):222-226, 2000

12. Hacker RJ, Cauthen JC, Gilbert TJ, et al: A prospective randomized multicenter clinical evaluation of an anterior cervical fusion cage. Spine 25:2646-2655, 2000

13. Kettler A, Wilke HJ, Claes L: Effects of neck movements on stability and subsidence in cervical interbody fusion: an in vitro study. J Neurosurg 94 (Suppl 1):97-107, 2001

14. Lunsford LD, Bissonette DJ, Jannetta PJ, et al: Anterior surgery for cervical disc disease. Part 1: Treatment of lateral cervical disc herniation in 253 cases. J Neurosurg 53:1-11, 1980

15. Martin GJ Jr, Haid RW Jr, MacMillan M, et al: Anterior cervical discectomy with freeze-dried fibula allograft. Overview of 317 cases and literature review. Spine 24:852-859, 1999

16. Matge G, Leclercq TA: Rationale for interbody fusion with threaded titanium cages at cervical and lumbar levels. Results on 357 cases. Acta Neurochir 142:425-434, 2000

17. Matge G: Anterior interbody fusion with the BAK-cage in cervical spondylosis. ActaNeurochir 140:1-8, 1998

18. Melzack R, Torgerson WS: On the language of pain. Anesthesiology 34:50-59, 1971

19. Odom GL, Finney W, Woodhall B: Cervical disk lesions. JAMA 166:23-28, 1958

20. Plötz GM, Benini A, Kramer M: [Micro-technological anterior discectomy without fusion in cervical disk displacement with radicular symptoms.] Orthopäde 25:546-553, 1996 (Ger)

21. Riley LH Jr, Robinson RA, Johnson KA, et al: The results of anterior interbody fusion of the cervical spine. Review of ninety-three consecutive cases. J Neurosurg 30:127-133, 1969

22. Robinson RA, Smith GW: Anterolateral cervical disc removal and interbody fusion for cervical disc syndrome. Bull Johns Hopkins Hosp 96:223-224, 1955 (Abstract)

23. Robinson RA, Walker AE, Ferlic DC, et al: The results of ante- rior interbody fusion of the cervical spine. J Bone Joint Surg Am 44:1569-1587, 1962

24. Samii M, Völkening D, Sepehrnia A, et al: Surgical treatment of myeloradiculopathy in cervical spondylosis. A report of 438 operations. Neurosurg Rev 12:285-290, 1989

25. Savolainen S, Rinne J, Hernesniemi J: A prospective randomized study of anterior single-level cervical disc operations with long-term follow-up: surgical fusion is unnecessary. Neurosurgery 43:51-55, 1998

26. Sawin PD, Traynelis VC, Menezes AH: A comparative analysis of fusion rates and donor-site morbidity for autogeneic rib and iliac crest bone grafts in posterior cervical fusions. J Neurosurg 88:255-265, 1998

27. Smith AW, Robinson RA: The treatment of certain cervicalspine disorders by anterior removal of the intervertebral disc and interbody fusion. J Bone Joint Surg Am 40:607-624, 1958

28. Sonntag VKH, Klara P: Controversy in spine care. Is fusion necessary after anterior cervical discectomy? Spine 21: 1111-1113, 1996

29. Thalgott JS, Fritts K, Giuffre JM, et al: Anterior interbody fusion of the cervical spine withcoralline hydroxyapatite. Spine 24:1295-1299, 1999

30. van den Bent MJ, Oosting J, Wouda EJ, et al: Anterior cervical discectomy with or without fusion with acrylate. A randomized trial. Spine 21:834-840, 1996

31. van Limbeck J, Jacobs WC, Anderson PG, et al: A systematic literature review to identify the best method for a single level anterior cervical interbody fusion. Eur Spine J 9:129-136, 2000

32. Whitehill R, Barry JC: The evolution of stability in cervical spine constructs using either autogenous bone graft or methylmethacrylate cement. A follow-up report on a canine in vivo model. Spine 10:32-41, 1985

33. Wilke HJ, Kettler A, Goetz C, et al: Subsidence resulting from simulated postoperative neck movements: an in vitro investigation with a new cervical fusion cage. Spine 25:2762-2770, 2000

Manuscript received November 15, 2001.

Accepted in final form December 19, 2001.

Address reprint requests to: Alain Barth, M.D., Department of Neurosurgery, Inselspital, University of Berne, 3010 Berne, Switzerland. email: alain.barth@insel.ch. 